\title{
QUARTERLY PROGRESS REPORT
}

Report Title:

Type of Report:

Reporting Period:

Contact:

Date of Report:

DOE Award Number:

Submitting Organization: Membrane Technology and Research, Inc.

Subcontractors:

Other Partners:

Project Team:

\section{Disclaimer}

1360 Willow Road, Suite 103

Menlo Park, CA 94025

Tel: (650) 328-2228

Fax: (650) 328-6580

www.mtrinc.com

Field Demonstration of a Membrane Process to Separate Nitrogen from Natural Gas: Ninth Quarterly Progress Report

Quarterly progress report

April 1, 2004 through June 30, 2004

Dr. Kaaeid Lokhandwala

Tel: (650) 328-2228 ext. 140

e-mail:kaaeid@mtrinc.com

September 1, 2004

None

ABB Lummus Global

Project Officer: Anthony Zammerilli

Contract Specialist: Keith L. Carrington

This report was prepared as an account of work sponsored by an agency of the United States Government. Neither the United States Government nor any agency thereof, nor any of their employees, makes any warranty, express or implied, or assumes any legal liability or responsibility for the accuracy, completeness, or usefulness of any information, apparatus, product, or process disclosed, or represents that its use would not infringe privately owned rights. Reference herein to any specific commercial product, process, or service by trade name, trademark, manufacturer, or otherwise does not necessarily constitute or imply its endorsement, recommendation, or favoring by the United States Government or any agency thereof. The views and opinions of authors expressed herein do not necessarily state or reflect those of the United States Government or any agency thereof. 


\begin{abstract}
The original proposal described the construction and operation of a $1 \mathrm{MMscfd}$ treatment system to be operated at a Butcher Energy gas field in Ohio. The gas produced at this field contained 17\% nitrogen. During pre-commissioning of the project, a series of well tests showed that the amount of gas in the field was significantly smaller than expected and that the nitrogen content of the wells was very high (25 to 30\%). After evaluating the revised cost of the project, Butcher Energy decided that the plant would not be economical and withdrew from the project. Since that time, Membrane Technology and Research, Inc. (MTR) has signed a marketing and sales partnership with ABB Lummus Global, a large multinational corporation. MTR will be working with the company's Randall Gas Technology group, a supplier of equipment and processing technology to the natural gas industry. Randall's engineering group has found a new site for the project at a North Texas Exploration (NTE) gas processing plant.
\end{abstract}

The plant produces about 1 MMscfd of gas containing 24\% nitrogen. The membrane unit will bring this gas to $4 \%$ nitrogen for delivery to the pipeline. The membrane skid is being built by ABB. NTE has ordered the required compressor and MTR is making the membrane modules. The membrane skid is scheduled to be completed by December 29. Our target is to have the unit installed and optimized by mid-January.

\title{
Table of Contents
}

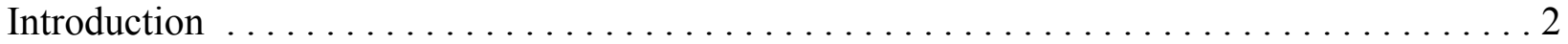

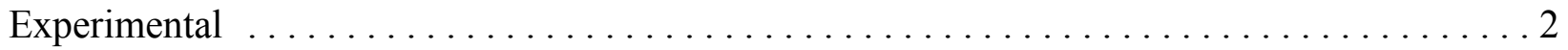

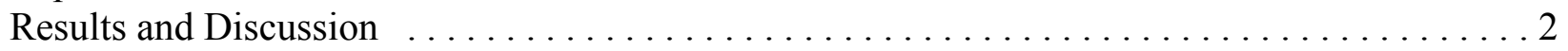

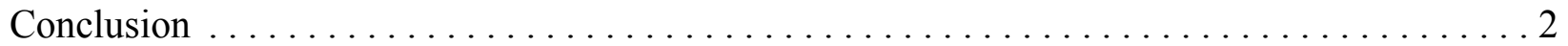

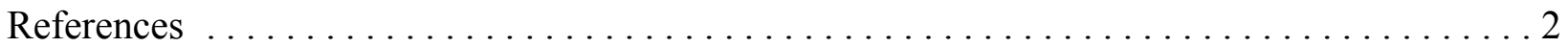

\section{Introduction}

The natural gas specification for inert gases is less than 4\%. On this basis, about $17 \%$ of known U.S. reserves of gas are subquality due to high nitrogen content. Some of this gas can be brought to pipeline specifications by dilution with low-nitrogen-content gas; some is treated by cryogenic condensation and fractionation. Nonetheless, about 1.0 trillion scf of known reserves are currently shut in.

This project covers the first demonstration of a new membrane technology to treat this otherwise unusable gas. The objective of this project is to develop a membrane separation process to separate nitrogen from high-nitrogen-content natural gas. To demonstrate the process, a proof-of-concept plant is being built at a North Texas Exploration (NTE) gas field in Texas/Oklahoma.

Additional test sites are also being explored. 


\section{Experimental}

The membrane system was installed and started up at the NTE site. The client was expecting to get a minimum of $1 \mathrm{MMscfd}$ of inlet gas but had been able to produce only about $0.6 \mathrm{MMscfd}$. The inlet gas is water saturated and this caused problems during compression. In this reporting period, these problems were actively pursued and fixed. The compression equipment is now operating in a stable range and we expect to have the site operating at 50\% capacity shortly.

\section{Results and Discussion}

North Texas Exploration (NTE), ABB and MTR have signed an agreement, through which MTR/ABB will supply NTE with a fully-fabricated skid-mounted membrane unit including 28 eight-inch membrane inserts housed in eight pressure vessels. The process flow diagram of the proposed system is shown in Figure 1.

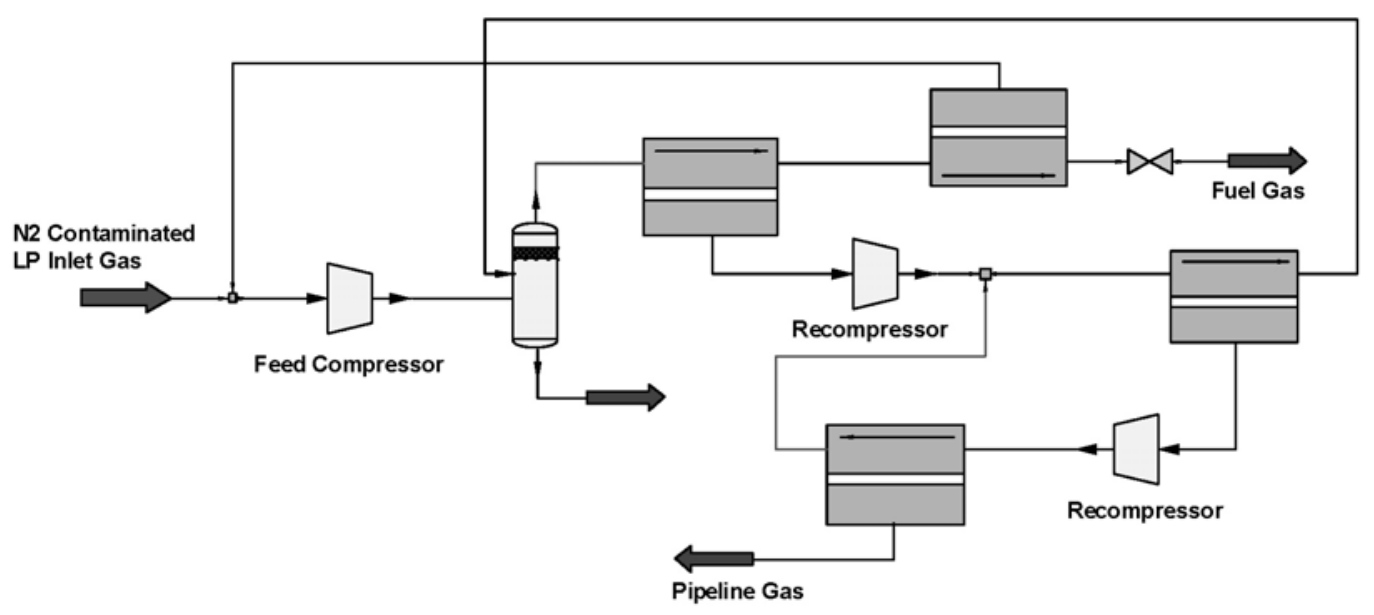

Figure 1. Process flow diagram from the NTE Pilot Plant System.

The low pressure N2 contaminated gas will be compressed to about 800 psia and will be introduced into the membrane skid after passing through a filter coalescer. The gas will pass through a set of membranes in two steps. In the first step ( 8 membrane inserts) partially enriched natural gas will be produced as a permeate gas and will be routed after compression to a second stage for further purification. The non-permeate from the first step will enter the second step (8 membrane inserts), in which further methane recovery will be affected. This permeate stream will be routed to the inlet compression. The non-permeate from the second step will be routed to fuel for the compression. The partially purified gas from the first step will be further purified two more stages of membrane, one containing 8 membrane inserts and the second containing four membrane inserts. To produce the final pipeline quality natural gas. 
The membrane skid fabrication was completed and is shown in Figure 2.

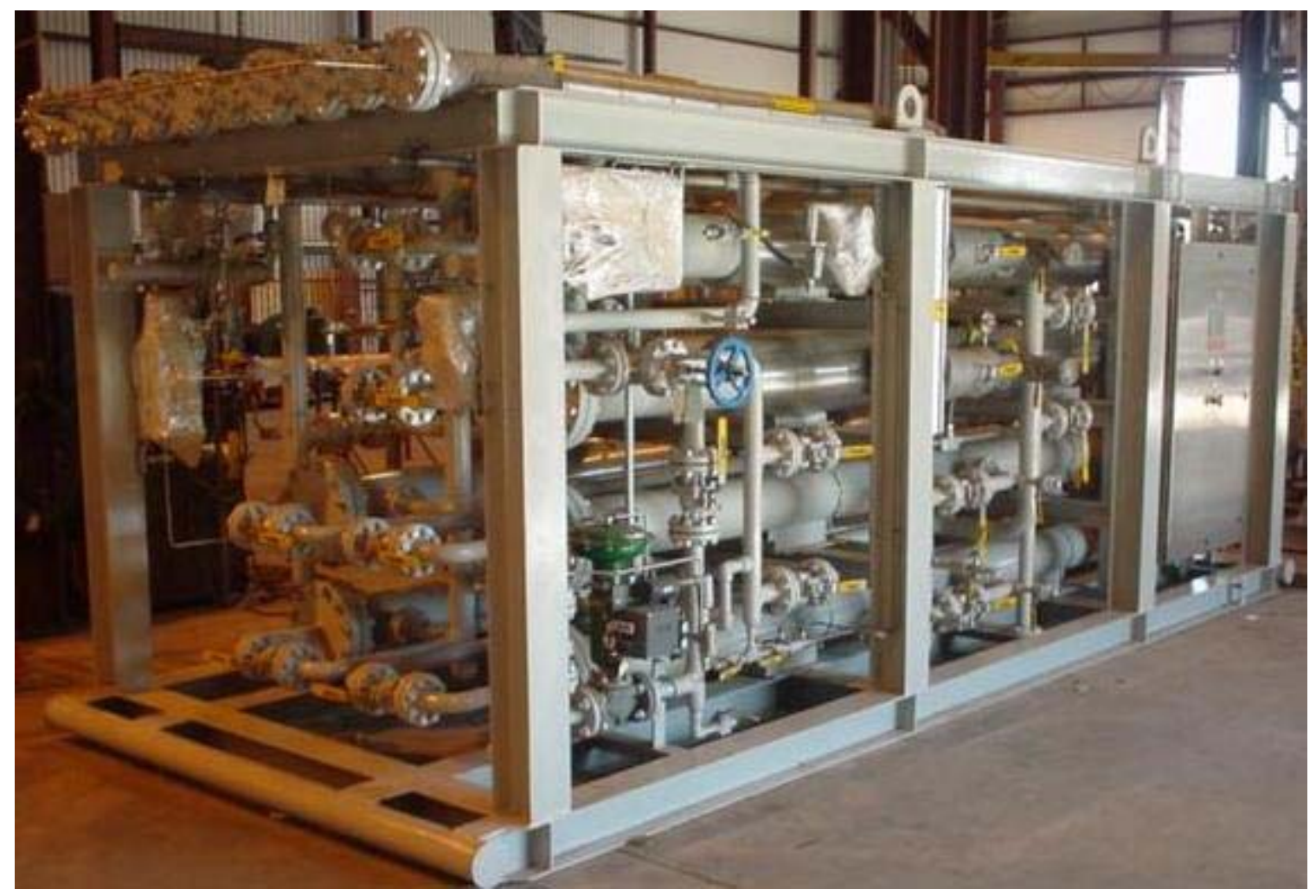

Figure 2. Membrane skid for NTE pilot test.

A photograph of the system being installed in the field is shown in Figure 3. 


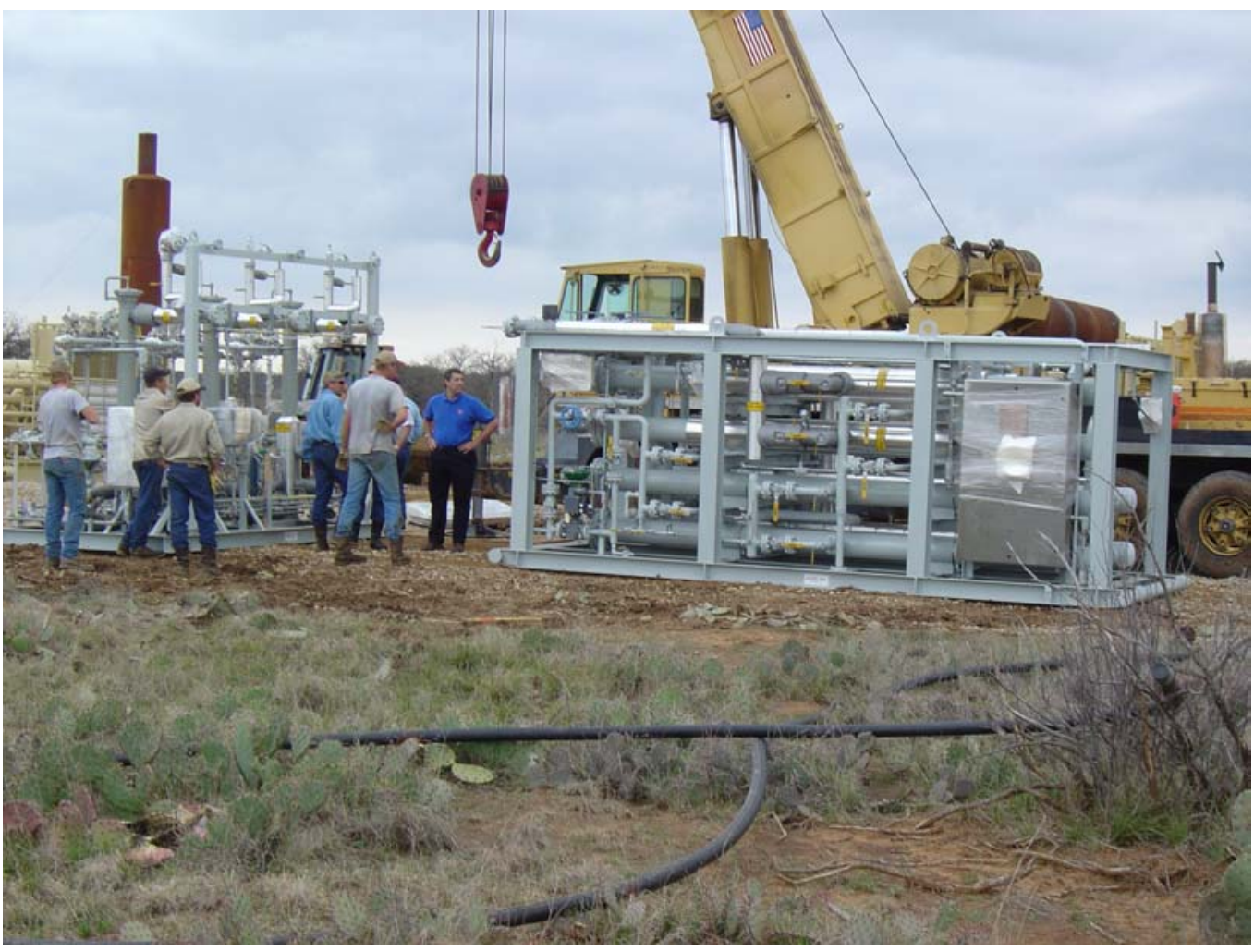

Figure 3. Membrane system being installed at Green Ranch, TX.

\section{Additional Field Sites}

MTR signed a leasing contract, shipped the unit and had it installed at the Louisa, KY site in June. The system was started up under MTR supervision and within hours of installation and startup was producing pipeline quality gas. The process design for this test unit is as shown in Figure 4. 


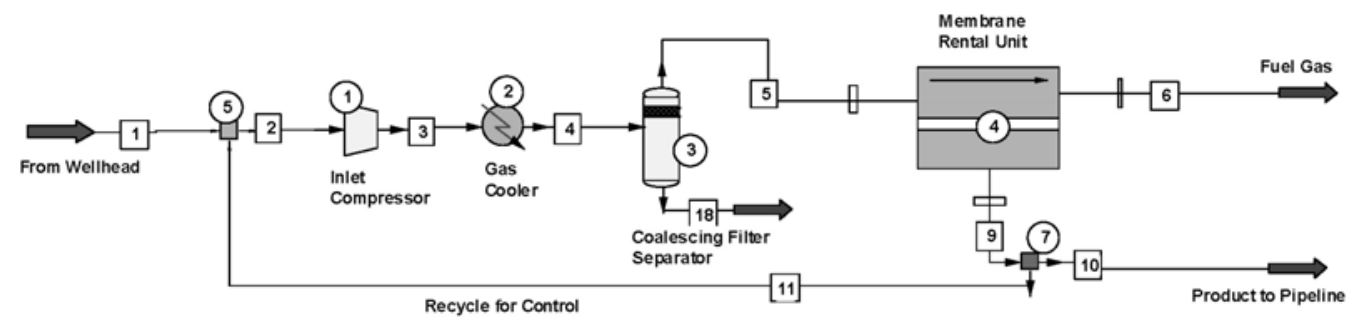

Figure 4. Process flow diagram for system at Louisa, KY.

The gas from the wellhead will be compressed to a minimum of 300 psia and will pass through a cooler to reduce the temperature to a maximum of $120^{\circ} \mathrm{F}$. The gas will then pass through a filter coalescer/separator to remove any entrained water or hydrocarbon liquids and mist. The aerosol-free gas will then enter the membrane skid. The gas will pass through a scrubber and enter the membrane cartridges. Methane and other hydrocarbons will preferentially permeate the membrane and will be removed as product gas. The non-permeated stream will exit the membrane skid at about the same pressure as the inlet and will be throttled down in a valve to the fuel gas pressure. Any excess gas will be flared/vented. The product gas line will go through a $\mathrm{T}$ junction. One arm of the $\mathrm{T}$-junction will be piped into the suction side of the compressor after passing through a regulator valve. The other arm of the T-junction will be routed to the pipeline entry point. This pipe may also need a regulator valve to control flow and pressure.

The expected performance of the Louisa, KY membrane system is shown in Table 1. 
Table 1. Expected Feed and Products Streams

\begin{tabular}{|c|c|c|c|c|c|}
\hline $\begin{array}{l}\text { Stream No. } \\
\text { Stream Name }\end{array}$ & $\begin{array}{c}1 \\
\text { Feed }\end{array}$ & $\begin{array}{c}5 \\
\text { Membrane Feed }\end{array}$ & $\begin{array}{c}6 \\
\text { Fuel Gas }\end{array}$ & $\begin{array}{c}11 \\
\text { Recycle }\end{array}$ & $\begin{array}{c}10 \\
\text { Pipeline }\end{array}$ \\
\hline Temp F & 76 & 120 & 91.3867 & 105.6933 & 105.6933 \\
\hline Pres psia & 30 & 300 & 282 & 45 & 45 \\
\hline Vapor mole fraction & 1 & 1 & 1 & 1 & 1 \\
\hline Total Ibmol/h & 5.49 & 9.59 & 0.48 & 4.10 & 5.01 \\
\hline Total Ib/h & 109.62 & 191.63 & 9.36 & 82.02 & 100.25 \\
\hline Total std L gpd & 907.37 & 1594.84 & 66.83 & 687.60 & 840.40 \\
\hline Total std V MMscfd & 0.05 & 0.09 & 0 & 0.04 & 0.05 \\
\hline \multicolumn{6}{|l|}{ Component mole \% } \\
\hline Helium-4 & 0.00 & 0.00 & 0.00 & 0.00 & 0.00 \\
\hline Carbon Dioxide & 0.03 & 0.03 & 0.00 & 0.03 & 0.03 \\
\hline Oxygen & 0.21 & 0.21 & 0.17 & 0.21 & 0.21 \\
\hline \begin{tabular}{|l|} 
Nitrogen \\
\end{tabular} & 5.67 & 4.77 & 27.72 & 3.57 & 3.57 \\
\hline Methane & 79.00 & 79.34 & 70.90 & 79.78 & 79.78 \\
\hline Ethane & 9.42 & 9.76 & 1.07 & 10.21 & 10.21 \\
\hline Propane & 4.23 & 4.40 & 0.13 & 4.62 & 4.62 \\
\hline I-Butane & 0.28 & 0.29 & 0.00 & 0.31 & 0.31 \\
\hline $\mathrm{N}$-Butane & 0.73 & 0.76 & 0.00 & 0.80 & 0.80 \\
\hline I-Pentane & 0.11 & 0.11 & 0.00 & 0.12 & 0.12 \\
\hline N-Pentane & 0.11 & 0.11 & 0.00 & 0.12 & 0.12 \\
\hline $\mathrm{N}-\mathrm{Hexane}$ & 0.21 & 0.22 & 0.00 & 0.23 & 0.23 \\
\hline
\end{tabular}

The Louisa., KY test system has been operating since installation and has been producing pipeline quality gas. We are now negotiating the sale of a full commercial unit which is expected to be ordered in the $3^{\text {rd }}$ Quarter 2004.

\section{Conclusions}

Several initial teething issues have been resolved and the system is now under stable operation as far as compression is concerned. The complete system will be commissioned and product gas will be produced by the end of September. NTE, the company hosting this test site/pilot plant will be drilling additional wells to increase inlet flow rate. The system is expected to be fully operational continuously in September, 2004.

\section{References}

None cited. 